\title{
The geography of Irish voter turnout: A case study of the 2002 General Election
}

\author{
Adrian Kavanagh 1 , Gerald Mills ${ }^{2}$ and Richard Sinnott ${ }^{3}$ \\ ${ }^{1}$ NIRSA, National University of Ireland, Maynooth \\ ${ }^{2}$ Department of Geography, University College Dublin \\ ${ }^{3}$ Geary Institute and Department of Politics, University College Dublin
}

\begin{abstract}
'Turnout' is a key measure of participation in the democratic process. Specifically, it measures the proportion of eligible voters that turns out to vote on election day. Low (or declining) turnout rates are a cause of concern and are often taken as a measure of disaffection with the political decision-making process. In Ireland, turnout in the 2002 general election confirmed a downward trend in voter participation and represented the lowest turnout since the foundation of the State. However, turnout rates vary markedly across the State. Until recently, it was not possible to examine turnout at a sufficiently detailed geographical scale to allow systematic analysis of the potential causes of such variations. This paper reports on a joint project, involving the Geary Institute, UCD and the National Institute for Regional and Spatial Analysis (NIRSA), NUI Maynooth, that is undertaking a comprehensive analysis of turnout in the 2002 general election at the lowest possible level of aggregation. Here, a cartographic description and introductory analysis is presented that includes the first ever electoral-district-level map of turnout. The resulting geographical patterns are generally coherent and explicable and provide important pointers for future research. In an unanticipated finding, this map shows that the phenomenon of low turnout in urban areas occurs beyond the main cities and their suburbanised hinterlands and shows up as a characteristic of most provincial towns.
\end{abstract}

Key index words: turnout, electoral-district map, patterns.

\section{Introduction}

'Turnout' is a key measure of voter participation in the democratic process. Specifically, it measures the proportion of eligible voters that turns out to vote on election day. For most people in Ireland this act requires a journey to a polling station on a prescribed day. A high turnout rate is regarded as indicative of a healthy democracy where citizens participate and elected officials have strong mandates. In contrast, low (or declining) turnout rates are a cause of concern and are frequently interpreted as a measure of disillusionment with the political process. In Ireland, turnout in the 2002 general election confirmed a downward trend in voter participation that began in 1982 (see Figure 1) and, twenty years later, culminated in the lowest turnout for an Irish general election since the foundation of the State. This general election trend is mirrored in similar declines in participation rates for other types of elections over the same period.

There are two approaches to the analysis of the problem of low turnout, each approach having distinctive advantages and disadvantages. One approach is based on individual-level data gathered by means of sample surveys. Data of this kind have the advantage of being able to get at a wide range of variables, including social-psychological variables, and of being able

Irish Geography, Volume 37(2), 2004, 177-186. 


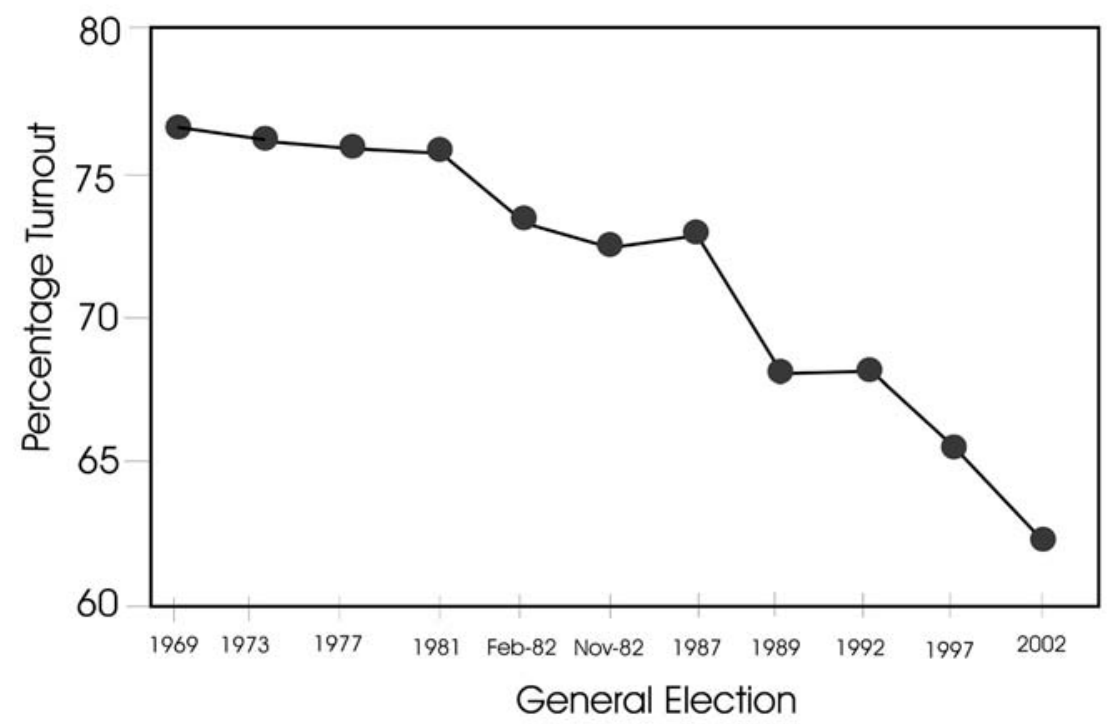

Figure 1: Voter turnout in Irish general elections, 1969-2002.

to make direct inferences about the behaviour of individuals. However, individual-level data suffers from the problem of overestimation of turnout and from the related problem of potential biases in survey response rates that lead to the under-representation of non-voters in the sample. The second type of data - aggregate data - is subject to problems arising from the limited range of variables that can be accessed in seeking explanations of low turnout and to problems of cross-level inference that arise in any attempt to make inferences about individual-level behaviour from aggregate-level data (Achen and Shively, 1995). However, the big advantage of aggregate data lies in the accuracy of the estimation of the dependent variable (turnout) and in the potential it offers for spatial and census-based analysis of variations in that dependent variable. The lower the level of aggregation to which the data relate the better, both from the point of view of the number of cases available for analysis and from the point of view of getting at the substantial variation that can occur within constituencies.

A joint project, involving the Geary Institute, UCD and the National Institute for Regional and Spatial Analysis (NIRSA), NUI Maynooth, is currently undertaking a comprehensive analysis of turnout levels in the 2002 general election at the lowest possible level of aggregation. This project has been made possible by the availability, following the 1997 Electoral Act, of marked copies of the electoral register. Coding of these data led to the calculation of turnout in over 3400 Irish electoral divisions, forming the largest ever data set for an area-based analysis of turnout in Ireland .

The purpose of the present paper is to use the data just described to undertake a cartographical analysis of turnout in the 2002 general election. The paper presents the first electoral-district-level map of turnout in an Irish election and analyses this and maps of two sub-national areas (Dublin and Laois-Offaly) with a view to identifying the spatial variations involved and to forming hypotheses as to the social, economic and political factors that underpin them. 
Previous aggregate analysis of turnout in the 1984 European Parliament election and in the combined 1989 general and European Parliament elections in Dublin using ward-level data tentatively pointed to the negative impact of social deprivation, and the positive impact of age and owner occupancy (Sinnott and Whelan, 1992). However, the findings were particularly tentative because the data were limited to the Dublin area. Further aggregatelevel analysis of turnout covered a series of six elections from 1981 to 1992 country-wide. Results of that analysis identified the positive influence of the proportion of farmers in a constituency and of the proportion with middle class occupations; it also brings out the negative impact of the proportion of young people and suggests that the influence of the first two of these three factors was variable from election to election (Sinnott, 1995: 140-42). However, these results also remained tentative because analysis of a series of elections could only be conducted at the cost of working at quite a high level of aggregation (Dáil constituencies) and consequently with a relatively small number of observations (the 41 constituencies).

\section{The data underlying the present project}

The 1997 Electoral Act greatly improved access to turnout data at a low level of aggregation by allowing for the release of marked copies of the electoral registers for local, European and general elections (but not for referendums). It is now possible to calculate accurate turnout figures for very small geographical areas (such as townlands, streets or housing estates) by counting the total number of marks on the register indicating who has voted in that polling station and relating these figures to the total numbers registered. The data can then be aggregated up to the electoral division (ED) level, which is suitable for computer cartography and for statistical analyses involving census data. Analysis of this kind of data from the 1999 European and local elections has been conducted for selected rural and urban constituencies (Kavanagh, 2002a and 2002b). Thanks to the Geary/NIRSA project, it now possible to undertake a systematic analysis of turnout in 2002 across the whole country.

\section{The cartography of turnout in 2002}

The national map: The national turnout map (Figure 3) shows substantial urban-rural differences in turnout in the 2002 general election. Thus, an area of low turnout stretches from Dundalk in the north-east, southwards through Louth and all but the very north-western parts of Meath, incorporating most of Dublin, Kildare and east Wicklow and extending as far south as Carlow on the inland side. This pattern corresponds with the locations of the main urban centres along the east coast and their extending commuter belts. The map also shows a clustering of low turnout EDs in and around the other main urban centres. This is most noticeable in Cork city and its surrounding areas, with low turnout also extending well beyond the immediate environs of the city into the eastern parts of county Cork. Pronounced low turnout is also found in and around Galway city, with concentrations of low turnout areas to the north and south of Galway Bay. Similar patterns of low turnout are evident in and around Waterford and Limerick cities.

One of the striking outcomes of this cartographic exercise is the discovery that the phenomenon of low turnout in urban areas occurs beyond the main cities and their suburbanised hinterlands and shows up as a characteristic of most provincial towns. These towns can generally be identified from the intersections in the national road network as shown in Figure 3 and are marked on the map by white dots. In the vast majority of cases these 
provincial-town markers are clearly associated with levels of turnout that are noticeably lower than turnout in the corresponding rural hinterlands.

On the other side of the turnout spectrum, the spatial distribution of high turnout can be summarised by reference to three main areas. Working from north to south, the first and largest more or less contiguous high turnout area might be somewhat freely labelled the 'north-west excluding Donegal'. This area stretches westwards from the Louth border, through Monaghan and the northern parts of Cavan, spreading out as it goes further westwards to include most of Longford, Roscommon, Leitrim, Sligo, Mayo and the north and much of the east of county Galway. The second area of high turnout can be thought of as the 'south-midlands' incorporating mainly the western parts of Laois and southern parts of Offaly and extending southwards to include most of Tipperary North, and parts of south-east Galway, north-east Limerick, and north-west Kilkenny. The third and final area of mainly high turnout can be labelled 'the south-west'. This consists of the south-west of county Limerick, the western half of county Cork, and almost all of county Kerry excluding Tralee, Killarney and the peninsular littorals.

In addition to the low and high-turnout areas that stand out on the national map and that suggest a strong urban-rural contrast, there are areas in which turnout shows a more motley pattern, alternating between the red, green and yellow colouring. The interpretation of these and other patterns will be discussed in the final section of this paper.

The Dublin map: Given the scale that is necessary to display turnout variations on the national map and given the substantially lower turnout in Dublin, the map in Figure 3 has the effect of obscuring turnout variations within the Dublin region. Accordingly, Figure 2 uses a different scale to analyse the geography of turnout in Dublin. The overall picture suggested by this almost wholly urban map shows a large concentration of low turnout in the inner city area (the area bounded by the Royal and Grand Canals and the inner circular road - see Figure 2) but also including the adjacent Drimnagh/Crumlin and Ranelagh/Rathmines areas located to the south of the Grand Canal. This core low turnout area is flanked on the north by a belt of high turnout, stretching westwards from Clontarf, Sutton and Howth on the east coast, through Drumcondra and parts of Cabra, into Castleknock and Lucan and extending southwards into the Newcastle and Rathcoole areas in the south-west of the region. In more or less parallel fashion, the inner core is flanked on the south side by fairly contiguous high turnout areas, running from Glasthule and Sandycove on the coast, westwards through Stillorgan, Foxrock, Dundrum, and on across to the Templeogue and Terenure areas. Outside these older and well established high turnout suburban areas to the north and to the south, there is an arc of low turnout going from the Darndale area in the north-east, through Ballymun, Mulhuddart and parts of Blanchardstown, southwards through Clondalkin, Cherry Orchard and Ballyfermot, into the West Tallaght area. Completing this arc is another area of low turnout in the extreme south of the region, including the Ballinascorney, Boheernabreena and Tibradden areas in the foothills of the Dublin Mountains, areas that have recently experienced considerable increases in their population. The issue of the implications of these patterns is taken up in the discussion section below.

A constituency map: In addition to the foregoing detailed analysis of the Dublin area, the spotlight has been turned on a mainly rural constituency, namely Laois-Offaly (Figure 4). The value of an analysis of Laois-Offaly is enhanced by its location between the low turnout Dublin commuter belt on its eastern borders, and high turnout areas, such as south Roscommon, east Galway and north Tipperary, on its western borders. The provincial town 


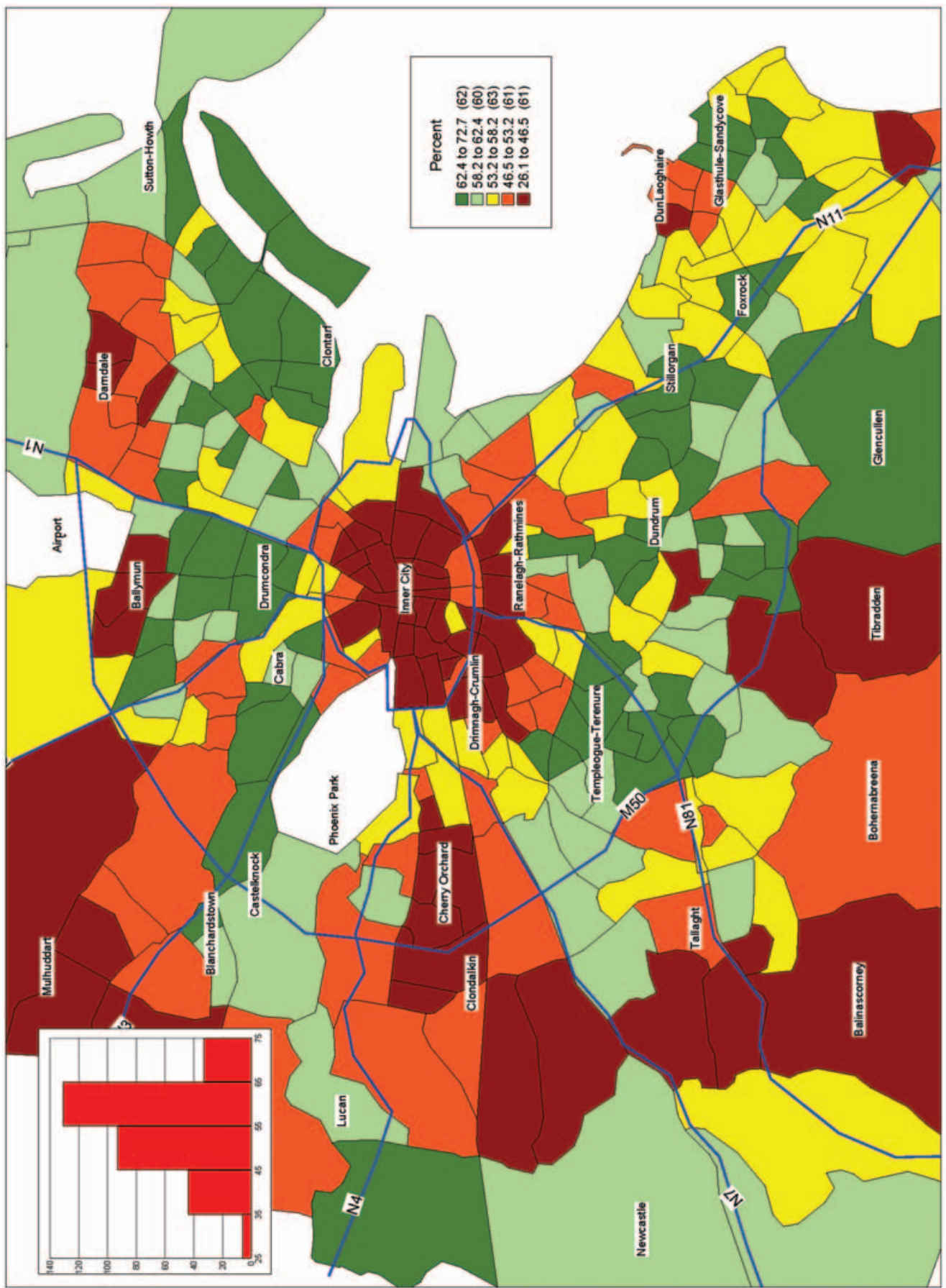

Figure 2: Turnout in Dublin in the 2002 general election. The map shows turnout, expressed as a percentage, in the Dublin urban area. Electoral divisions (EDs) to the north of this map, comprising the 'rural' part of the Dublin region (e.g. Garristown, Lusk and Skerries) are excluded, as are the largely unpopulated Phoenix Park and Airport EDs. For mapping purposes, quintiles were selected as the most appropriate classification system. 


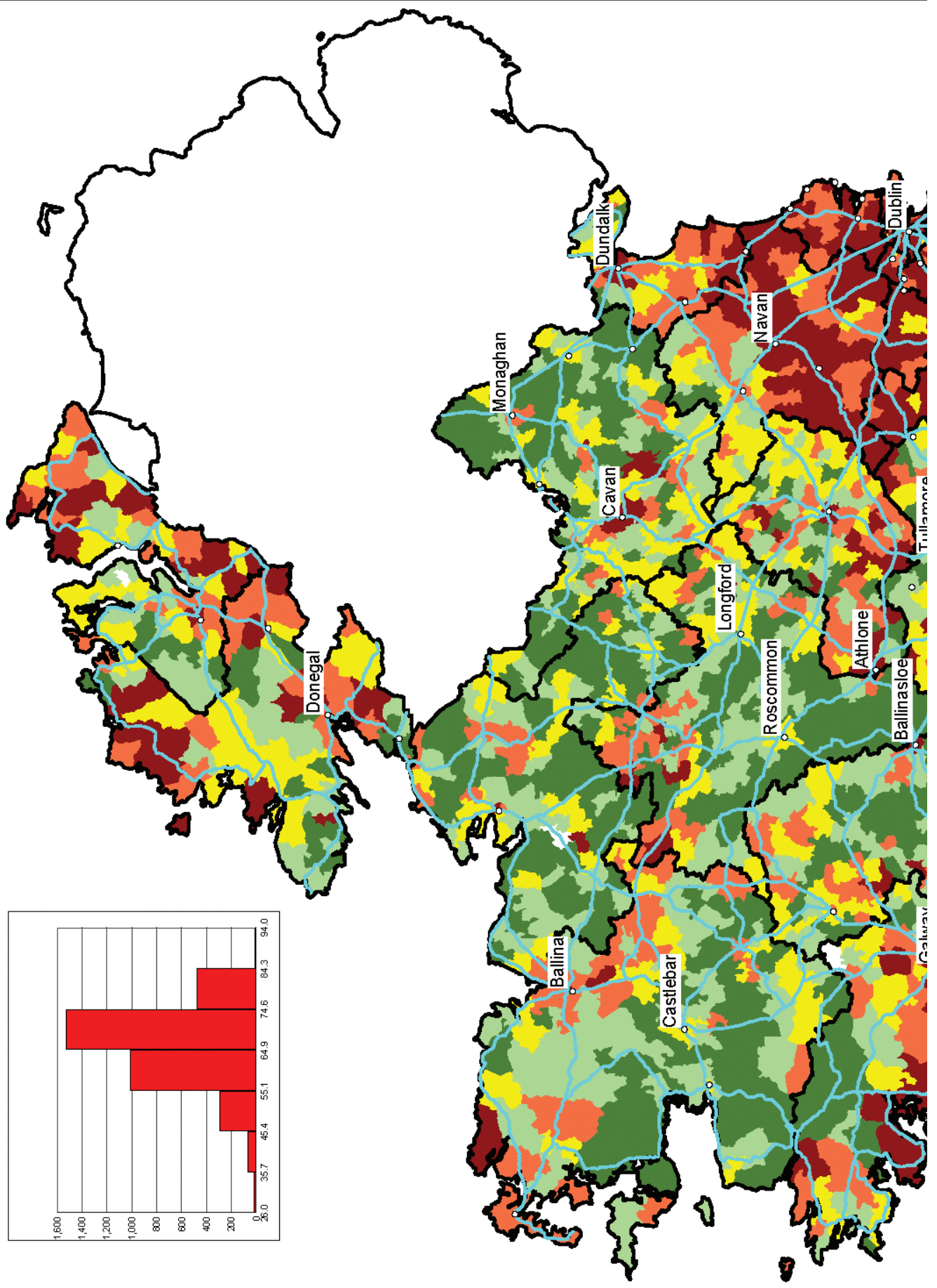

Figure 3: The national map of turnout in the 2002 general election. The units employed for mapping are Electoral Divisions (boundaries not shown) and the main areal units drawn are constituency boundaries. The national road system is shown in blue and major towns and cities (some of which are 


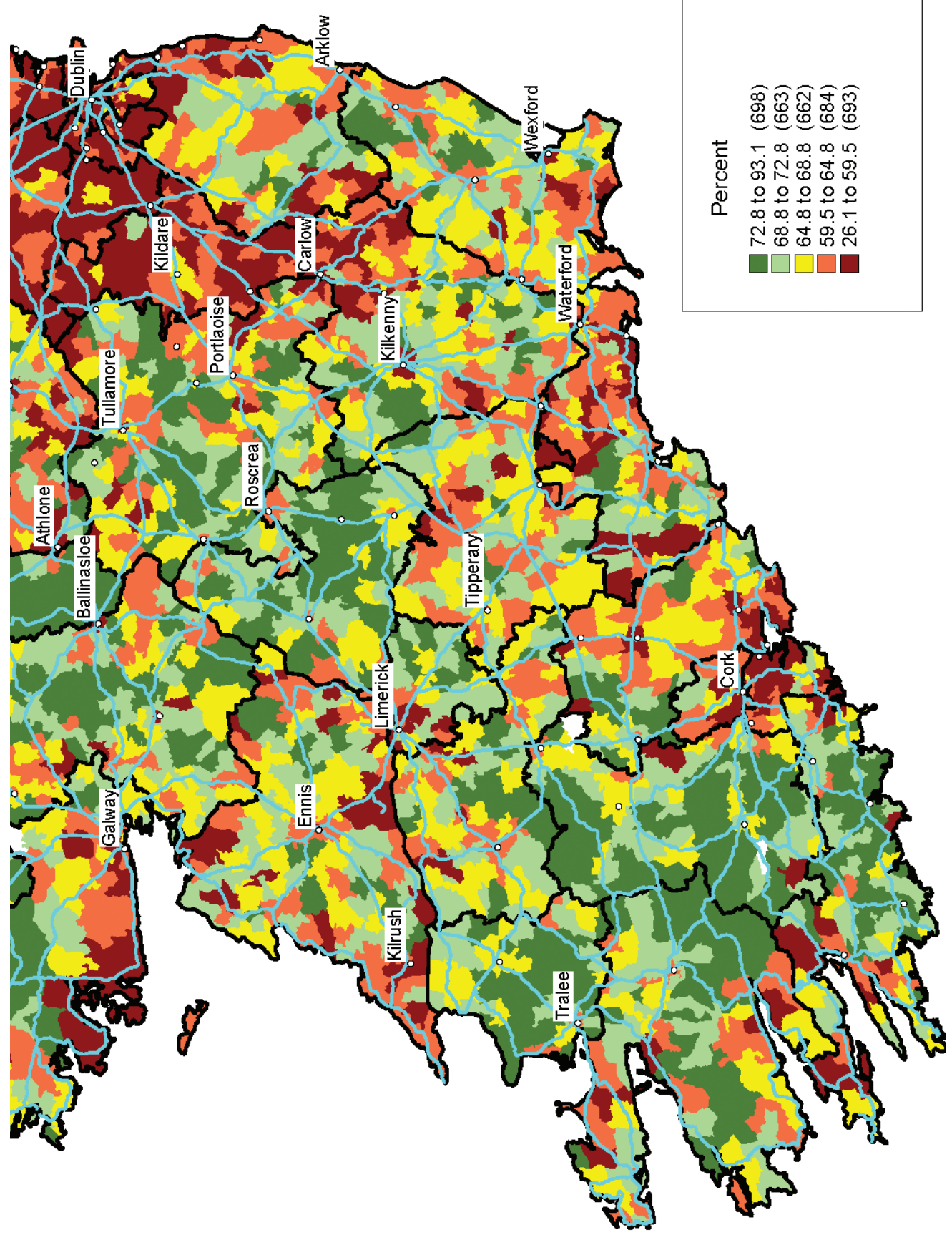

named) as white dots. The histogram in the upper left portion of the frame illustrates the frequency distribution of Electoral Divisions against turnout, expressed as a percentage. For mapping purposes, quintiles were selected as the most appropriate classification system. 


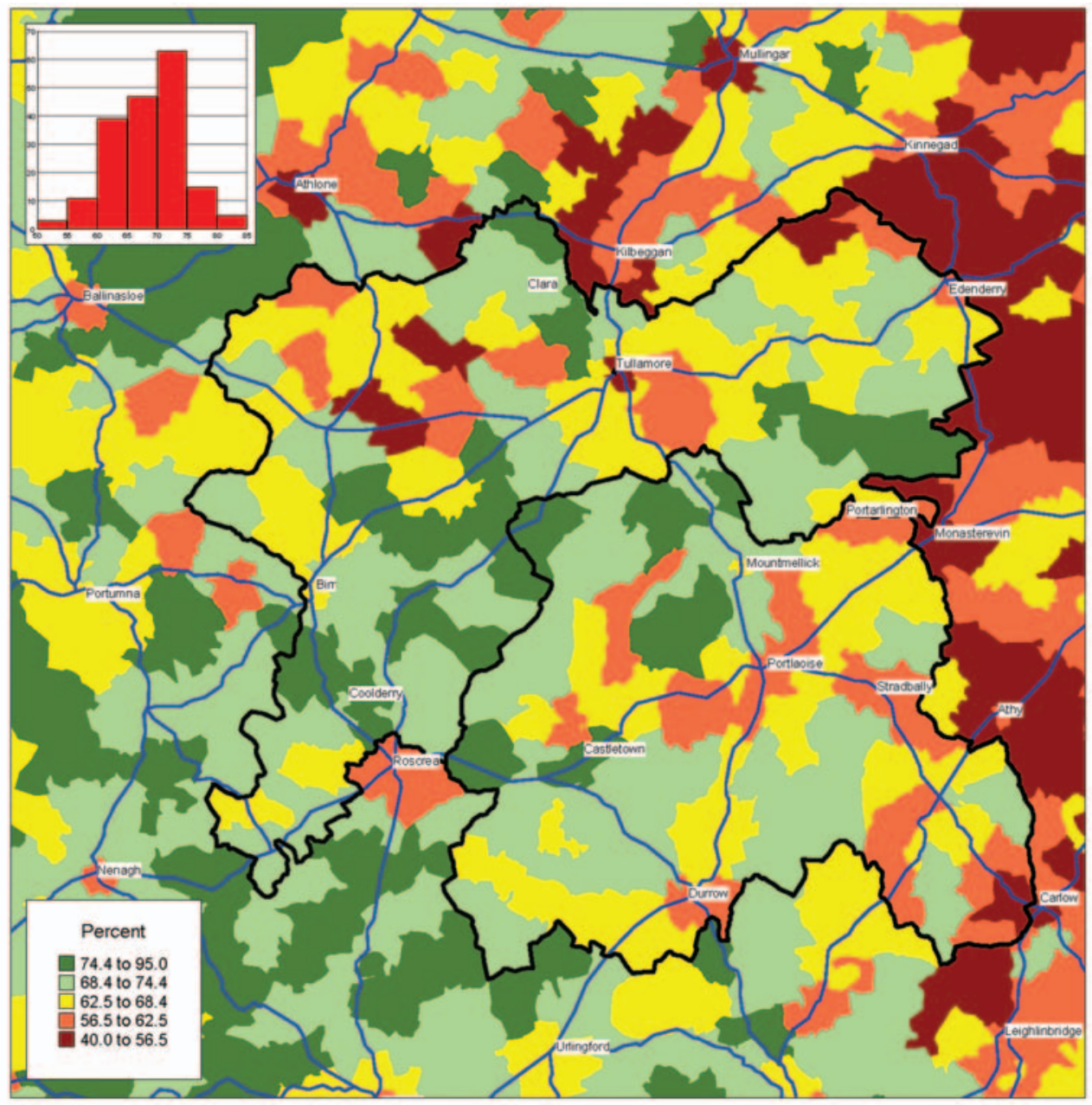

Figure 4: Turnout in the Laois-Offaly constituency in the 2002 general election. This map is centered on counties Laois and Offaly (shown by the lighter line), which comprise a single constituency. A statistically-based classification scheme is used to illustrate patterns referred to in the text. The frequency histogram shows the distribution of EDs within this constituency with regard to turnout.

effect that was a notable feature of the national map is even clearer at constituency level. The lowest turnouts in Laois-Offaly were associated with the larger towns of Portlaoise, Tullamore, Edenderry and Portarlington, some smaller towns such as Stradbally and Durrow, as well as the area in the south-eastern corner of the constituency, that forms the western environs of Carlow town, including the part of the town that falls within the borders of county Laois. Lower turnouts are also apparent along the eastern border of the constituency, encompassing the hinterlands of the neighbouring towns of Monasterevin and Athy as well as Carlow. A further striking feature of the map in Figure 4 is the strong association between lower turnout and the major routeways that pass through the constituency and link it to the Dublin region, as evidenced in the case of the N8 which marks a low turnout corridor through the constituency (see the route extending south-westwards from Monasterevin in the east to Portlaoise and on to Durrow in the very south of the constituency). One might find a hint here 
that turnout levels in much of the constituency may ultimately resemble those in neighbouring, low turnout, commuter belt constituencies to the east, such as Kildare North and Kildare South.

However, not all of the towns in Laois-Offaly have low turnouts. Towns such as Clara and - to a lesser extent - Mountmellick and Birr have relatively high turnout rates, while their immediate surrounding areas are high turnout areas in contrast to the low turnout areas that surround the other Laois-Offaly towns. The higher turnouts in these urban centres highlight the important influence that candidates can have on turnout. Clara, for instance, is the original political bailiwick of successful candidate Brian Cowen. Similarly, Mountmellick is the base of successful candidate, John Moloney, and Birr is the base of another successful candidate, Olwyn Enright. In short, candidate effects can mitigate low turnout tendencies in provincial towns.

\section{Discussion and conclusions}

The dominant finding of this cartographical analysis is undoubtedly the strength of the urban-rural contrast in voter turnout. This is exemplified in the lower turnout in and around Dublin, in the Dublin commuter belt, in the other main cities and in most of the provincial towns identified in the road network in Figure 3. The question is how to interpret this urbanrural contrast. One interpretation is that it is due to a stronger sense of community, more pervasive participatory norms and networks, and stronger political organisations and traditions in rural areas. An alternative (or complementary) explanation is that people in rural areas tend to be older and, as individual-level studies invariably show, older people vote more. Educational levels further complicate the picture. Education is conducive to turnout but is also inversely related to age. Thus the tendency for older people to vote and younger people to abstain, strong as it may be, is tempered by the tendency for less educated people to vote less and more educated people to vote more .

In addition to the overall urban-rural contrast, several other factors are reflected in these maps. The first, which comes across in the Dublin data, is a class effect that is clearly evident in the alternating belts of high and low turnout that surround the core of low turnout that marks central Dublin. However any class interpretation of these contrasts must also take account of the impact of residential stability/mobility and the presence or absence of community that such stability/mobility may be associated with. Thus high residential mobility alongside lower socio-economic status may contribute to the low turnout found in central Dublin, while high residential mobility along with higher socio-economic status may help to account for the equally low turnout found in parts of the Dublin outer ring and found also in the phenomenon of commuter-corridor abstention that is a marked feature of the Dublin-centred east-coast conurbation. This analysis also points to another feature that must be taken into account, namely political mobilisation. In many instances, this will take the form of mobilisation around particular prominent candidates, as in the bailiwick effects identified in Laois-Offaly. In other instances, political mobilisation will reflect particularly strong efforts by individual political parties. While such campaign effects are difficult to document in aggregate data, some progress can be made by integrating the data set used in this paper with tally data showing level of party support at electoral district level.

While all these interpretative issues undoubtedly pose major analytical challenges, which the authors are currently attempting to deal with, the basic descriptive observations set out in this paper remain valid and pertinent. These are, firstly, that turnout varies according to the 
urban-rural composition of an area and does so more substantially and more pervasively than has been previously demonstrated. Secondly, turnout varies by social class and by residential stability, though teasing out how precisely these factors affect turnout is rendered quite complex by the interaction of these variables with age and education. Tackling this aspect of the problem is clearly going to require multivariate analysis. The contribution of the cartographical analysis presented here is to establish the basic patterns that have been noted and to provide a platform from which a range of hypotheses can be generated and tested.

\section{Acknowledgement}

The authors gratefully acknowledge the funding support for this project provided by the Irish Research Council for the Humanities and Social Sciences (IRCHSS) and by the Higher Education Authority's Programme for Research in Third Level Institutions (PRTLI).

\section{References}

ACHEN, C.H. and SHIVELY, W.P. (1995) Cross-Level Inference. Chicago: University of Chicago Press.

ACHEN,C.H. and SINNOTT, R. (2004) The rational learning model of voter turnout. EU: Fifth Framework Project Working Paper.

KAVANAGH, A. (2002a) Unequal Participation, Unequal Influence: Voter participation and voter education in Dublin's south west inner city. Dublin: South West Inner City Network.

KAVANAGH, A. (2002b) Social Deprivation, Political Alienation and Community Empowerment: The geography of voter turnout in Ireland, 1997-2002, and its association with social deprivation. Unpublished $\mathrm{PhD}$ thesis. Maynooth: NUI Maynooth.

KAVANAGH, A. (2004) The 2004 local elections in the Republic of Ireland, Irish Political Studies, 19(2), 64-84.

LYONS, P. and SINNOTT, R. (2003) Voter turnout in 2002 and beyond, In: Gallagher, M., Marsh, M. and Mitchell, P. (eds) How Ireland Voted 2002. Basingstoke: Palgrave Macmillan, 143-58.

PARKER, A.J. (1982) The 'friends and neighbours' effect in the Galway West constituency, Political Geography Quarterly, 1(3), 243-63.

SINNOTT, R. (1995) Irish voters decide: Voting behaviour in elections and referendums since 1918. Manchester and New York: Manchester University Press.

SINNOTT, R. and WHELAN, B.J. (1992) Turnout in Second Order Elections: The case of EP Elections in Dublin, 1984 and 1989, The Economic and Social Review, 23(2), 147-66. 